\title{
DESIGN, ANALYSIS AND OPTIMIZATION OF 6 DOF ROBOTIC ARM
}

\section{DR. S. SOLOMON RAJ, DR. G. LAXMAIAH \& N. SANDEEP}

Department of Mechanical Engineering, Chaitanya Bharathi Institute of Technology, Telangana, India

Received: Jun 05, 2020; Accepted: Jun 25, 2020; Published: Jul 30, 2020; Paper Id.: IJMPERDJUN2020523

\section{INTRODUCTION}

In the highly developing society time and man power are critical constrains for completion of task in large scales.

The automation is playing important role to save human efforts in most of the regular and frequently carried works. One of the major and most commonly performed works in industry is picking and placing of jobs from source to destination.

Present day industry is increasingly turning towards computer-based automation mainly due to the need for increased productivity and delivery of end products with uniform quality. The inflexibility and generally high cost of hard-automation systems, which have been used for automated manufacturing tasks in the past, have led to a broad based interest in the use of mechanical arm capable of performing a variety of manufacturing functions in a flexible environment and at lower costs. The use of industrial mechanical arm characterizes some of contemporary trends in automation of the manufacturing process. However, present day industrial mechanical arm also exhibit a monolithic mechanical structure and closed-system software architecture. They are concentrated on simple repetitive tasks, which tend not to require high precision.

For the last few decades, robotics have played a very important role in process automation, with robot manipulators assuming a leading role in the development of several productive areas. Nowadays, industrial robots are used for the automation of a variety of tasks such as assembling, transfer of materials, all kinds of welding, precision cutting of materials, palletizing, painting, remote surgical procedures, among many possible applications [1,7].In general, industrial robots are employed to carry out repetitive jobs and/or those that require precision and speeds difficult to achieve by human beings. This has made it possible to improve the quality of products and the efficiency of their manufacturing $[2,3]$. Therefore, industrial robots are increasingly used in modern and automated production processes, as well as in hazardous applications, in which their use is clearly justified. On the other hand, 
industrial robots can perform tasks during many hours per day without getting tired or losing precision or effectiveness, because they are currently highly developed and robust devices that practically do not fail. Thus, to know, study, improve, reprogram, and adequate these systems to different scenarios becomes necessary, so users can profit as much as possible from them $[4,5]$. The present work arises from the compelling need of having less weight robots which can perform quickly as applied to pick and place operations.

\section{PROBLEM STATEMENT}

To solve the problems of pick and place of the cylindrical object having $6 \mathrm{~cm}$ diameter and 0.2 gram mass from one conveyor to another at room temperature in order to reduce human effort and efficient material handling. The distance between two conveyers is $50 \mathrm{~cm}$, and robotic arm should be suitable to work with six degree of freedom.

\subsection{Objectives}

The objectives in the current paper are design and analysis of six axes robotic arm. Modeling of the robotic arm and static analysis is carried out in Solid Works 17software [6]. The stress and strain analysis is carried out to see that the links are safe with regard to load carrying. Finally topology optimization is done to reduce the weight of the robotic arm.

\subsection{Design Parameters}

Many times it is difficult to judge the actual working co-ordinates including the degree of freedom, work-space coordinates of the prototype in the design stage. Following parameters are useful in modeling the robotic arm. Pay-load is $\mathbf{0 . 2} \mathrm{kg}$, maximum horizontal reach of $\mathbf{0 . 4 m}$ and the length of the longest link as $0.215 \mathrm{~m}$. The material for the arm is chosen as aluminum 1060 alloy having density $2700 \mathrm{~kg} / \mathrm{m}^{3}$, tensile strength $69 \mathrm{Mpa}$, yield strength $28 \mathrm{Mpa}$ and modulus of elasticity 69GPa. This material is chosen keeping in view the strength and light weight. Electrical actuators DC servo are chosen instead of hydraulic and pneumatic actuators because of the little power requirement and its light weight which is suitable for this purpose. The torque is fully balanced by the electric motors.

\section{MODELING}

The various parts of the robotic arm are modeled as shown in figure 1 . The assembled robotic arm is as shown in figure 2. table 1, table 2 and table 3 present specifications of articulated robotic arm, links and hybrid stepper motors respectively.

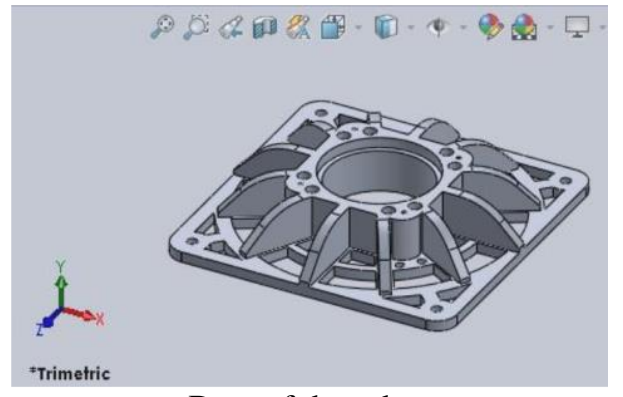

Base of the robot

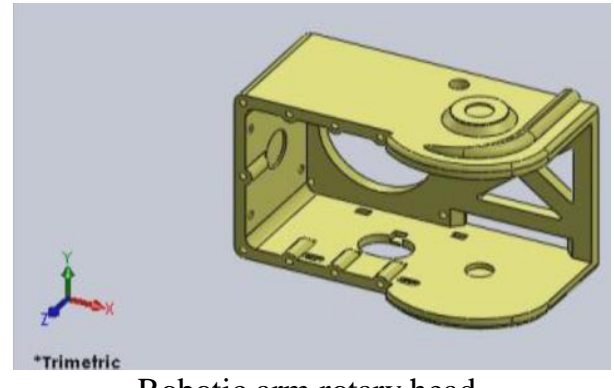

Robotic arm rotary head. 


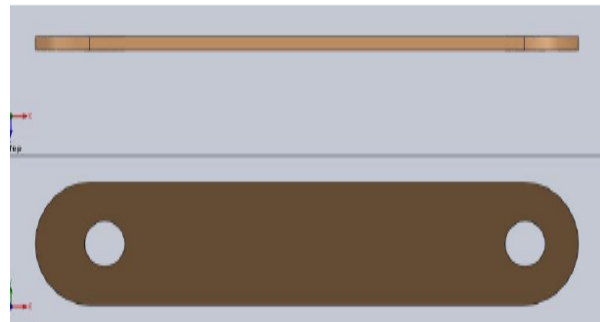

\section{Lower arm}

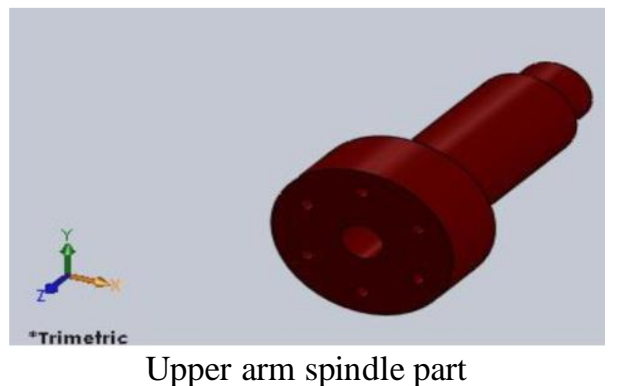

Upper arm spindle part

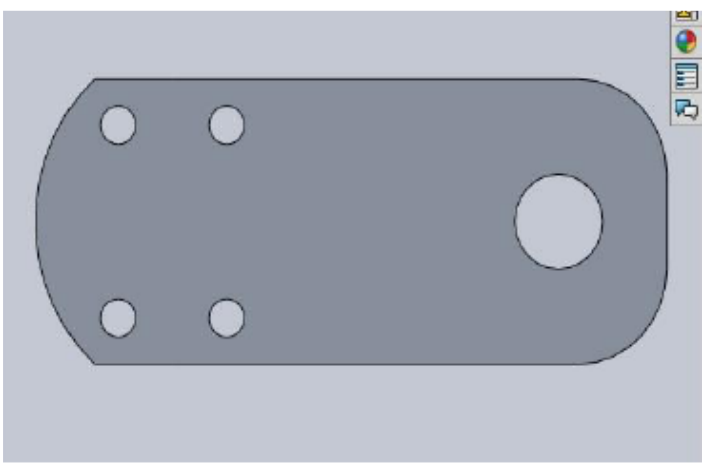

Arm part

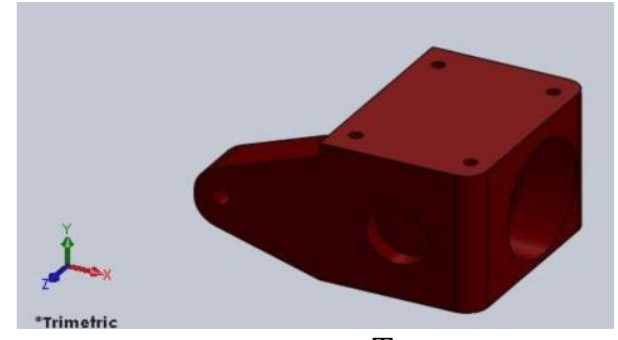

Turret

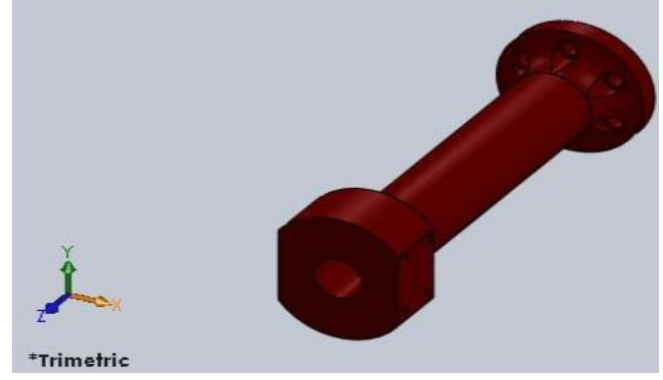

Boom

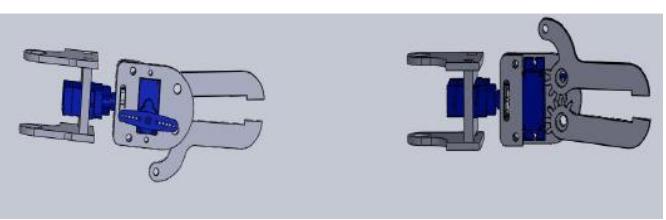

Front and back views of robotic arm gripper assembly

Figure 1: Parts of Robotic ARM.

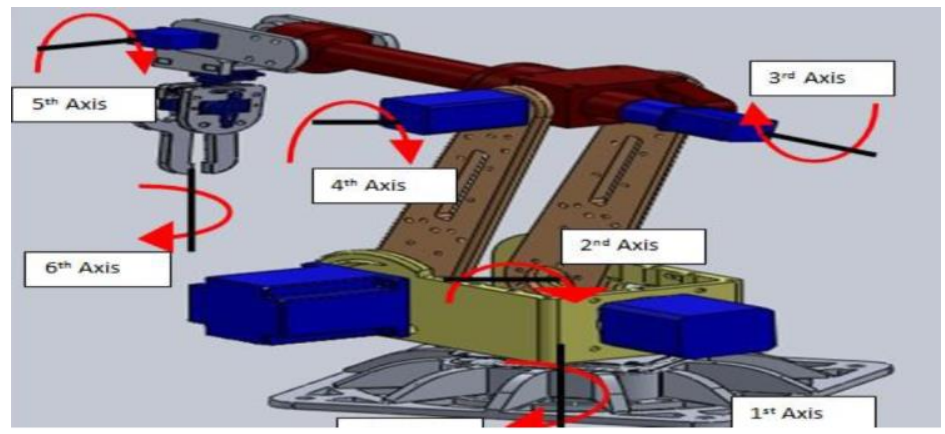

Figure 2: Assembly of Robotic Arm.

Table 1: The Specifications of Articulated Robotic Arm

\begin{tabular}{|l|l|}
\hline \multicolumn{1}{|c|}{ Specifications } & \multicolumn{1}{c|}{ Value } \\
\hline Number of axis & 6 \\
\hline Number of motors used & 7 stepper motors \\
\hline Max payload mass & 200gm \\
\hline Max reach & $410 \mathrm{~mm}$ \\
\hline Material & Aluminium 1060 \\
\hline \multicolumn{2}{c|}{ 2149 grams } \\
\hline
\end{tabular}


Table 2: Link Length, Mass and Angle of Rotation of Robotic Arm

\begin{tabular}{|l|c|c|c|}
\hline \multicolumn{1}{|c|}{ Link } & Length (Meters) & $\begin{array}{c}\text { Maximum Operating } \\
\text { Range in (Degrees) }\end{array}$ & Mass(kg) \\
\hline Base & 0.031 & 270 to -270 & 0.682 \\
\hline Rotaty head & 0.063 & 180 to -180 & 0.513 \\
\hline Lower arm & 0.215 & 155 to -105 & 0.430 \\
\hline Upper arm & 0.137 & 270 to -270 & 0.445 \\
\hline Wrist & 0.038 & 145 to -145 & 0.031 \\
\hline Gripper & 0.035 & 270 to -270 & 0.039 \\
\hline
\end{tabular}

Accordingly torques coming onto the different joints is calculated and stepper motors are selected. Following table indicates the details of the stepper motors.

Table 3: Specification of Hybrid Stepper Motors

\begin{tabular}{|l|c|c|c|c|}
\hline \multicolumn{1}{|c|}{ Stepper Motors } & Size $(\mathbf{m m})$ & Mass(kg) & Torque (n-m) & Quantity \\
\hline Nema 08 & $20 \times 20$ & 0.0091 & 0.036 & 2 \\
\hline Nema 11 & $28 \times 28$ & 0.0250 & 0.180 & 1 \\
\hline Nema 17 & $43 \times 43$ & 0.0350 & 0.440 & 1 \\
\hline Nema 23 & $57 \times 57$ & 0.1000 & 1.870 & 2 \\
\hline Nema 24 & $60 \times 60$ & 0.1900 & 4.000 & 1 \\
\hline
\end{tabular}

\section{RESULTS AND DISCUSSIONS}

The robotic arm has five joints and 6 degrees of freedom. Every joint has only one degree of freedom expect upper arm has two degree of freedom (two rotations). To do this, we must specify an axis for each joint to rotate around it. Any other kinds of movement are constrained. In this area, we discuss about the behaviour of the joints under loads and boundary conditions. Base is fixed as shown in figure 2and external loads like gravity 9.81 and force of $20 \mathrm{~N}$ are applied.

The meshing of the designed articulated arm robot is accomplished very cautiously to achieve good amount of stress distributions. By default, meshing provided by solid works is adopted and the part is simulated, from which a stress distribution patterns are obtained. The initial size of the mesh is 0.1 and the average element size is 0.2 . The local area mesh option in solid works is used to mesh high stress areas and element size is changed to 0.01 minimum and average element size is kept 0.02 . The local mesh control gives us the option to edit the density of the mesh at chosen area. The mesh adjusts itself according to the shape of the geometry. The shape of the element is tetrahedral and during the final stages of simulation, it is made sure that every geometry has at least 2 lakh elements. The meshed finite element model is shown in figure 3 . The maximum stress obtained at the end Effector is $27 \mathrm{Mpa}$ as shown in figure 4 and the maximum strain is 0.0026 as shown in figure 5. The deformation occurred is as presented in figure 6 . The maximum deformation as evidenced is $2 \mathrm{~mm}$ at the end Effector.

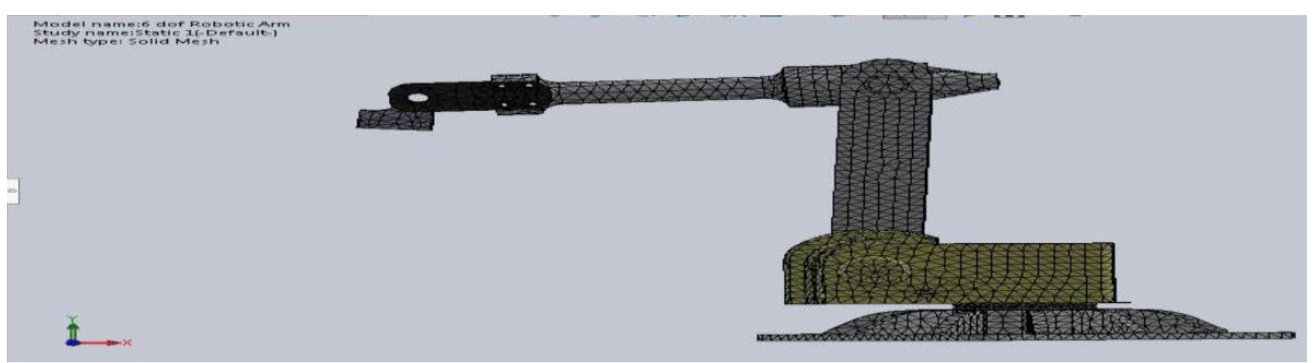

Figure 3: Meshed Model of Robotic Arm. 


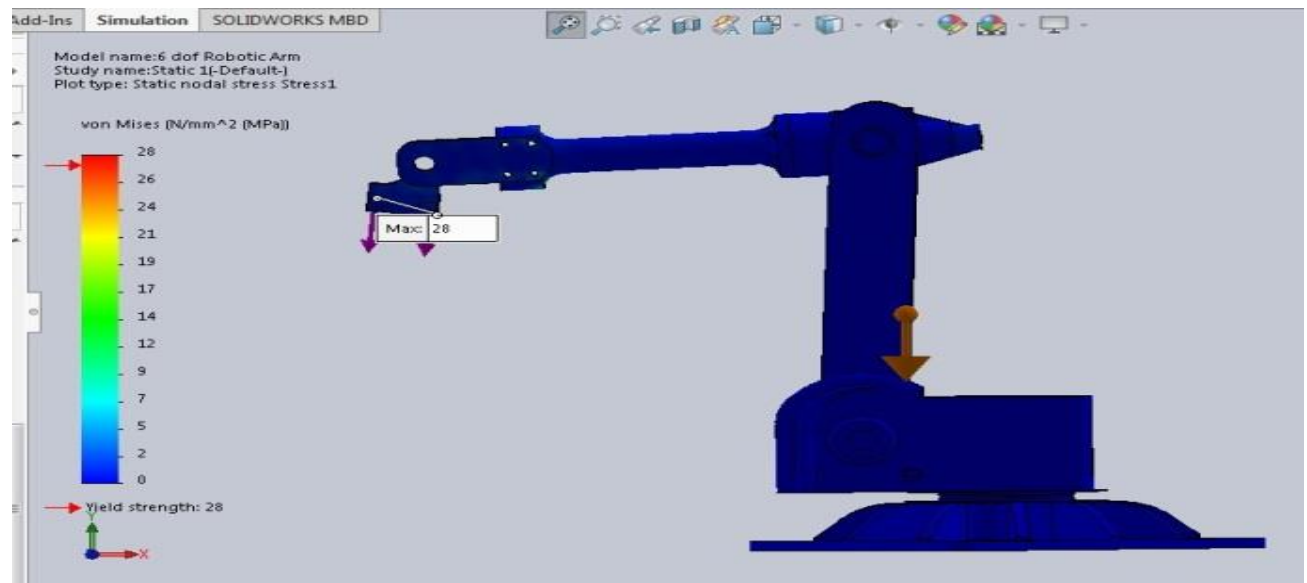

Figure 4: Von-Mises Stress Distribution.

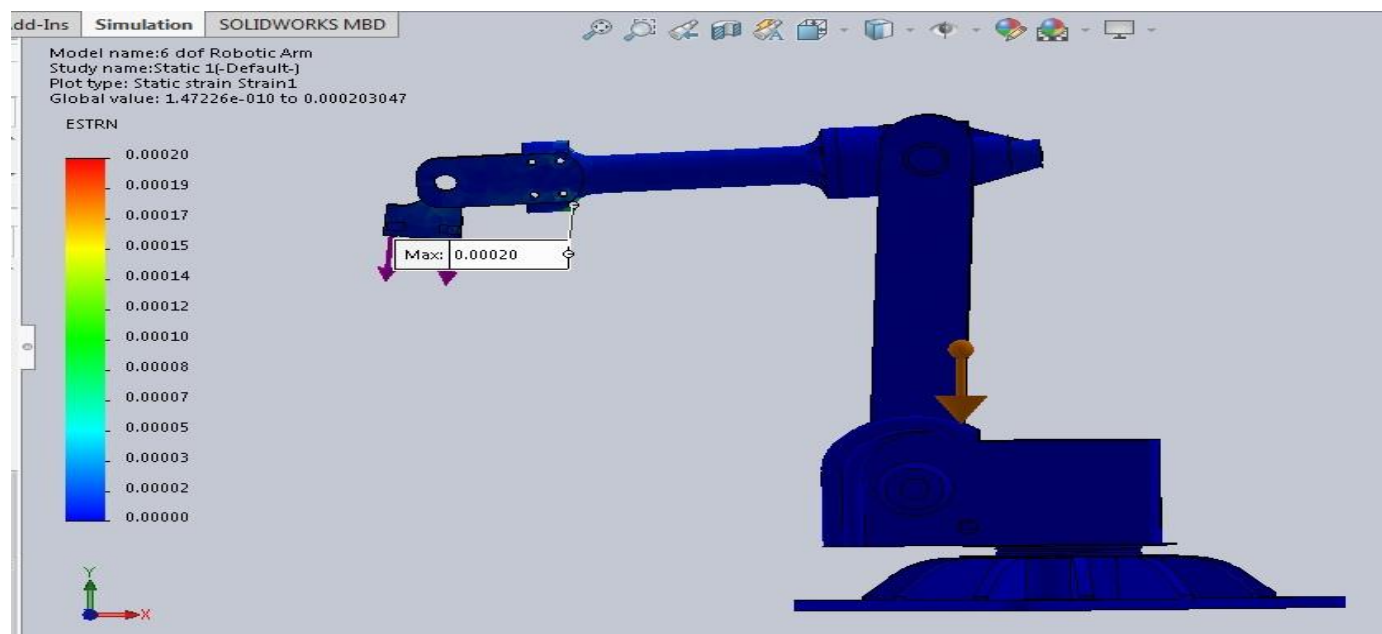

Figure 5: Von-Mises Strain Distribution.

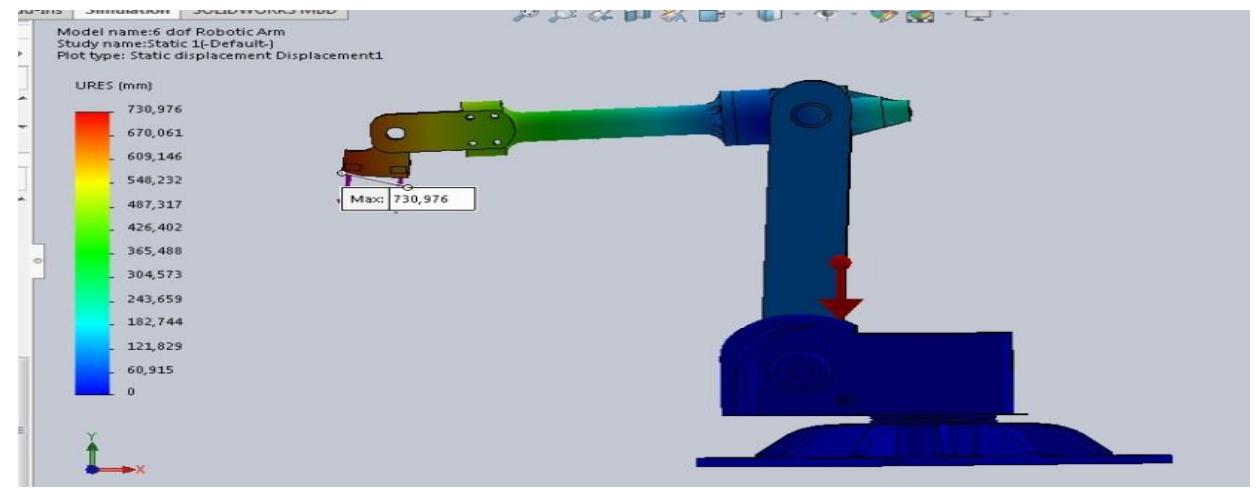

Figure 6: Deformation Distribution.

\section{OPTIMIZATION}

Servomotors are used in industrial robots because of their precise positioning control and stable structures and the cost of those motors increases in proportion with their torque. A robot with a lifting capacity between 5 and $7 \mathrm{~kg}$ has about $300 \mathrm{~kg}$ 
average weights. Especially the second axis motor carries $70-75 \%$ of the robot's total weight. Considering the high acceleration of robot arms, it will be better to use a more powerful motor. Therefore, it is important to select a different material with same strength or to change the geometric structure of the same material to get a reduced motor load. When the articulated robots extend their arms in full and horizontally, the torque caused by robot's own weight is extremely high. In addition to that, when the robot is loaded at its maximum capacity, the stress on the second axis arm is increasing and it is growing closer to the rotation axis. Since it would heterogeneously increase the amount of deformation, concentration of stress on a narrow region is an undesired situation. If those loads could be dispersed by a geometrical change, particularly on the second axis arm, deformation at the tip of the robot will be decreased. The lower arm which constitute a major portion of the weight is modified to make is light weight. The optimized lower arm is as shown in fig 5, where stress is distributed to higher areas making a link almost of uniform strength.
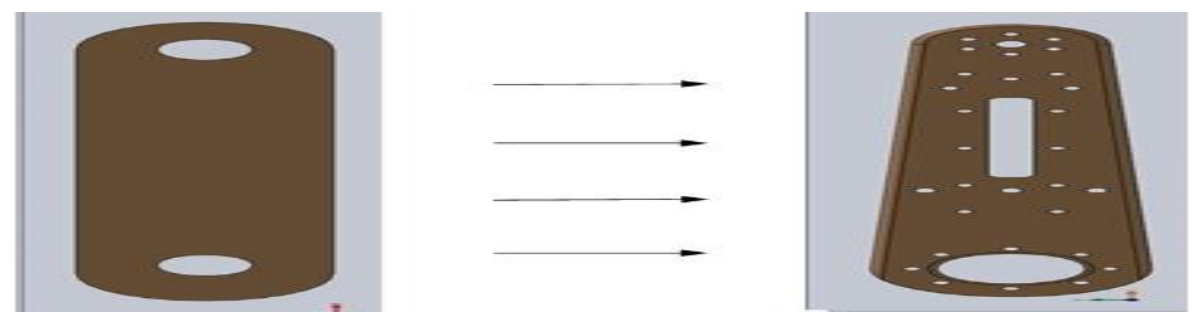

Figure 5: Modified Lower Arm.

The modified link specifications are as presented in table 4 . Net of $0.257 \mathrm{~kg}$ mass has come down for the whole configuration.

Table 4: Comparison of Masses of Links before and after Modifications

\begin{tabular}{|l|c|c|c|}
\hline & $\begin{array}{c}\text { Mass(kg) } \\
\text { (Initially) }\end{array}$ & $\begin{array}{c}\text { Mass(kg) } \\
\text { (Modified) }\end{array}$ & Change in Mass(Kg) \\
\hline Base & 0.682 & 0.640 & -0.042 \\
\hline Rotary head & 0.513 & 0.403 & -0.11 \\
\hline Lower arm & 0.430 & 0.325 & -0.105 \\
\hline Upper arm & 0.445 & 0.445 & -- \\
\hline Wrist & 0.031 & 0.040 & +0.009 \\
\hline Gripper & 0.039 & 0.039 & -- \\
\hline
\end{tabular}

\section{CONCLUSIONS}

In this paper, a 6axis robotic arm has been successfully designed and is analyzed for strength to avoid failure. A four axis robotic arm is taken as reference which is available in industry used for pick and place operations. Two additional axes are created to increase the flexibility and reach of the existing four axis robot. The material used for the links of the robotic arm is $\mathrm{Al} 1060$ alloy. The robotic arm is modelled in Solid works 17, knowing link lengths and material. The total mass of robotic arm turned out to be 2149 grams. FE analysis is done by using solid works simulation tool. Static analysis is performed to calculate the stresses by considering the forces. From the results it is concluded that the maximum von-Mises stress occurred is $27 \mathrm{Mpa}$, which is well below the yield strength of the material. Shape optimization is done to lower arm, which constitute most of the weight, with an intention to reduce the weight and increase the efficiency of stepper motor. The percentage of weigh reduction as obtained from the results is $12 \%$. 


\section{REFERENCES}

1. Lopez, 1.,Castelan, M., Castro, F. J., Pena, M., \& Osorio, R. (20l3). Using object's contour, form and depth to embed recognition on capability into industrial robots, Journal of Applied Research and Technology, 11(1),5- 17.

2. Gandhi, K. R. U. T. A. R. T. H., et al. "Motion controlled robotic arm." International Journal of Electronics and Communication Engineering (IJECE) 2.5 (2013): 81-86.

3. Ben-Gharbia. K. M., Maciejewski, A. A., \&Roberts, R. G. (20 14). A kinematic analysis and evaluation of planar robots designed from optimally fault-tolerant Jacobin s. IEEE Transactions on Robotics, 30(2), 516-524.

4. Deshpande, Vivek, and P. M. George. "Kinematic Modelling and Analysis of 5 DOF Robotic Arm." International Journal of Robotics Research and Development (IJRRD) 4.2 (2014): 17-24.

5. Zabbar, MdAjijulBin, and ChistyNafiz Ahmed. "Design \& Implementation of an Unmanned Ground Vehicle (UGV) Surveillance Robot." International Journal of Electrical and Electronics Engineering (IJEEE) 5.6 (2016): 2278-9944.

6. Urrea, c., \&Kern, 1. (2014). Position control of a redundant robot with 5 DOF of the SCARA industrial manipulator type,Jokall, $J$.

7. Gomez, A., Lafuent e, P. D., Rebollar, c., Hernandez, M. A., Olgufn. E. H., Jimenez,II \&Rodriguez, 1. (20 14). Design and construction of a didactic 3-dof parallel links robot station with a l-dofgripper, Journal of Applied Research and Technology, 12(3), 435-443.

8. Yap, Hwajen, et al. "Development of an Augmented Reality-Based G-Code Generator in a Virtual Cnc Milling Simulation. "International Journal of Computer Science and Engineering (IJCSE) 5. 2, Feb - Mar 2016, 63-72

9. Siciliano, B., \& Khatib, O. (2008). Springer handbook of robotics (1st ed.).Berlin: Springer.

10. Documentation of Solid Works 17.

11. Md. Anisur Rahman, et.al, American Journal of Engineering Research (AJER)e-ISSN 2320-0847 p-ISSN : 2320-0936Volume02, Issue-10, pp-298-307Design, Analysis andImplementation of a Robotic Arm-The Animator

\section{AUTHORS PROFILE}

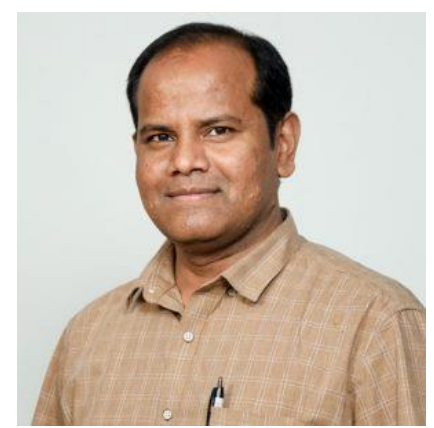

Dr. S. Solomon Raj working as Associate Professor Professor in the department of Mechanical Engineering, Chaitanya Bharathi institute of technology (CBIT), Hyderabad, obtained his BTech in Mechanical Engineering from Kakatiya Univarsity, Warangal (2000). Later, hodid his M Tech in Solid Mechanics and Design from IlT Kanpur (2004).He has completed his Ph.D from Osmania University (2017) in the area of Composite Materials. Hehasputin16yearsofTeachingexperionce.HisAreasof Interests are Solid Mechanics, Machine Design, Composite Materials, Mechanical Vibrations and Finite Element Analysis. He has published Research Papers in International level journals and 
conferences

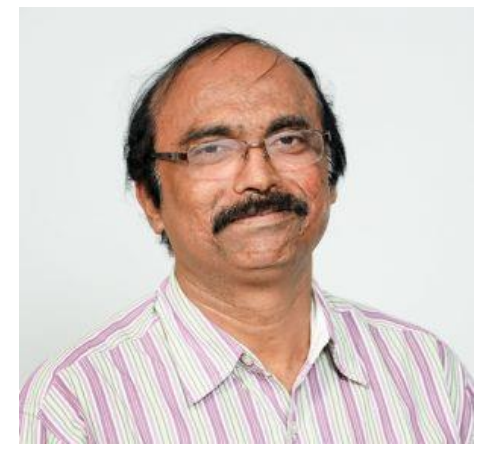

Dr G Laxmaiah is working currently as a Professor in the department of Mechanical Engineering, Chaitanya Bharathi institute of technology (CBIT), Hyderabad, graduated from Nagarjuna University in 1993 and obtained his postgraduation with Machine Design from Andhra University in 1996. He obtained his PhD from Osmania University in 2013. He has 23 years of teaching experience. He has published 15 papers in various national and international journals and conferences. His area of research is Design and Vibrations. Presently he is guiding 4 Ph.D scholars. He is the member SAE and life member of ISTE, New Delhi.

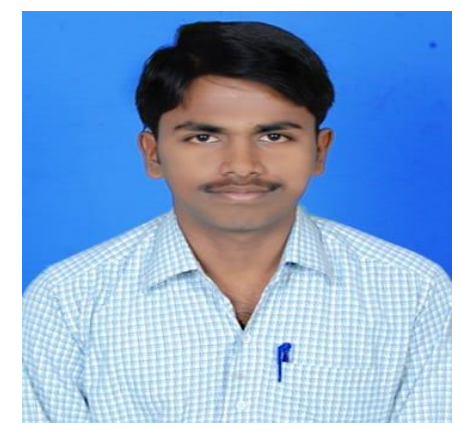

N Sandeep is an M.Tech Student in CAD/CAM specialization. He has Graduated with a degree in Mechanical Engineering from Jawaharlal Nehru Technological University Hyderabad in 2016 and obtained his post-graduation specialization in CAD/CAM from Osmania University in 2019. He has 2 years of industrial experience in industrial design. 